\title{
Development of Foreign Language-Based Apps for Supporting Immigrants ${ }^{1}$
}

\author{
Jin-Young Kim and Jae Yeong Lee \\ Hankuk University of Foreign Studies, 107 Imun-ro, \\ Dongdaemun-gu, 130-791, Seoul, Korea \\ staci21@naver.com,jylee@hufs.ac.kr
}

\begin{abstract}
The Korean government has implemented many multicultural policies in the recent years in order to support marriage immigrants. However, most of the programs designed to them basically help the immigrants' daily living. In addition, the programs are ysually conducted on the spot such as the Multicultural Family Support Centers in the neighborhood. Thus, the immigrants with low income, who are likely to be forced to enter a job market, hardly make access to the centers in time of need. Consequently, 1 out of 3 marriage immigrants appeared that they have never gotten servicês at the centers. With this economic disadvantage, some Korean spouse hesitate to help their wife or husband adapt to Korean society sooner than they expect. This eluctance results from purchasing marriages, which may require substantial amoant of time tobuild a mutual trust. In this context, multicultural support programs focused on marriageimmigrants should develop online that provides more direct and easy way to approach information as well as offline programs. This study suggests that foreign language-based apps can help immigrants acquire knowledge and information to live an independent life in Korea.
\end{abstract}

Keywords: marriage immigrants, the multicultural family, foreign language-based apps, smartphone, information literacy

\section{Introduction}

Since 2000, Korea has been dranatically undergoing demographic changes mainly due to the influx of marriage immigrants and migrant workers. In addition, globalization has helped increase exchanges of human and material resources so that the number of people who entered Korea reached 50 million which is almost tantamount to the entire population of Korea in August, 2012. According to the statistics of Korea Immigration Service, the number of foreigners living in Korea as of March, 2013 reached 1.47 million, which is 3.7\% increase from the previous year [1]. Marriage immigrants whom the Korean government focuses on by implementing most of multicultural policies account for 149,000 and about the half comprises naturalized citizens.

Compared to migrant workers, the marriage immigrants are a small number, however, the government perceives them as Korea citizens because of their sedentary living legally acquired by marrying a Korean. That is, most of multicultural policies tend to be focused on marriage immigrants despite the hue and cry of other immigrant groups. It may result from a strong bond underlying blood-tied Korean society.

Thus, marriage immigrants are apparently supposed to be integrated into the mainstream, yet, the reality is not exactly what it should be. In 2012, the Ministry of Gender Equality and Family conducted a comprehensive survey on the present condition of multicultural families in the nation. The Ministry has done this survey every 3 years

\footnotetext{
1 This paper was supported by Hankuk University of Foreign Studies Research Fund.
} 
since 2006 to understand the circumstances that multicultural families face and have a general idea in establishing necessary institution for them in the future. The report reveals the fact that approximately 1 out of 5 marriage immigrants suffered loneliness due to an emotional maladjustment, which increased $4.5 \%$ from the previous survey of the year 2009. Although the immigrants' length of stay has been elongated and their employment rate higher, the social network appears to be rather weakened.

Accordingly, it is essential to provide immigrants with more customized policies and information to expand the labor market and to integrate the immigrants into Korean society. Furthermore, the number of children from the multicultural family reached more than 160,000 as of 2012. A highly-competitive country like Korea may be likely to compel immigrants to adopt unwanted method regarding child-rearing, which causes frustration and stresses. In this regard, this research argues that existed support policies focused on the multicultural families should be complemented with deploying IT devices such as tablet PCs and smartphones in order to directly provide information in time of need.

\section{The Online Multicultural Support Systems}

In the late 1980's, Korea's economy emerged as one of the newly industrializing economies in East Asia along with Taiwan, Hong Kong, and Singapore. Expanding economy attracted a lot of labor force into Korean industries especially manufacturing businesses as well as other sectors such as agriculture and fisheries. The government implemented the Industrial Trainee System o eke out thelabor shortage and as a result, the migrant workers mainly from Southeast Asian countriesentered Korea under the work permit directed by the government. However, the government, then, neglected welfare of the migrant workers.

The major influx of immigrants has becomenoticeable since 2000's. The vacantization of rural areas caused by rapid Industrialization left many marriageable- aged men unmarried unintentionally. In addition, the low birth rate and aging phenomenon worsened a marriage market in Korea. Many Korean parents used to prefer boys to girls, which led to the gender) imbalance. Namely, a surge in international marriages has resulted from the problems embedded in Korean society.

Unlike migrant workers, the marriage immigrants are easily considered to be Korean or Koreanized by being provided with necessary support to live in Korea. The Ministry of Gender Equality and Fanily has established 205 multicultural support centers all over the nation as of 2013. They support marriage immigrants and their family in the community giving person-to person services including Korean education, legal, medical, translating and interpreting services. Yet, the problem is that, despite a number of services providing, 1 out of 3 peoplestill remain unaware of the centers according to the survey. Even though they know, many of the immigrants have never visited the centers in their neighborhood before The reasons for such indifference can vary. Many multicultural families comprise a large proportion of low class in the nation, $41.9 \%$ with less than the income of 2 million won per month (the Korean family $17 \%$ ). Thus, more and more marriage immigrants tend 10 be driven into a labor market instead of seeking ways to enhance their educational capital. Also, some Korean husbands hesitate to help their spouse to have the abilities to adapt Korean society sooner than they expected. Unfortunately, this reluctance, possibly caused by purchasing marriage or floods of distorted images of international couples shown through media, still prevails among multicultural families.

Then, the easy access to multicultural programs can be very a helpful solution for marriage immigrants to learn to adapt a new life in Korea. The Multicultural Family Center established a portal website Danuri 2 (www.liveinkorea.kr) that provides immigrants with comprehensive supports being a state-of-the-art platform by meeting the

\footnotetext{
2 Literally, da means 'many' and nuri refers to 'world' in Korean.
} 
convenience of immigrants in 8 different languages 3 from employment support, nationality acquisition consultation, life guidance to education, emergency support and Korean conversation support(translation and interpretation services).

Danuri also operates a hot-line system in case of emergency. This portal website was constructed in 2010 after the Multicultural Family Support Act was enacted in 2007. Korea is perceived as an IT-powerhouse. However, according to the Ministry of Culture and Tourism, out of 347 governmental bodies in relation to multicultural policies, only 188 organizations offer comprehensive information online, which accounts for 54\%. In table 1, the types of online contents developed for immigrants are mainly focused on daily living, scholarship information, culture, employment and publicity of events held in the community. Most of these online contents are made onto a form of web-pages and metadata.

Table 1. The Types of Digital Contents for Immigrants

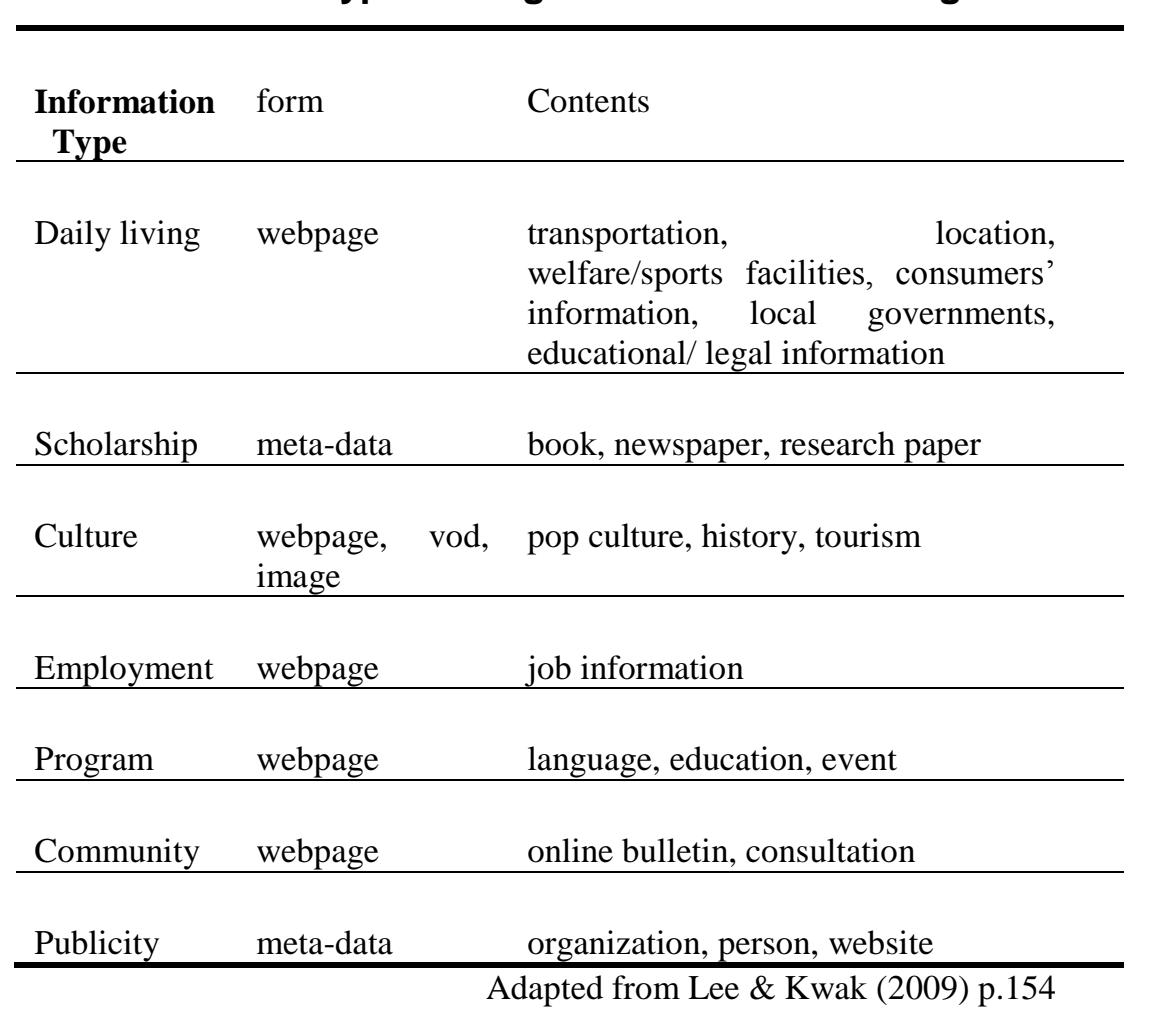

Besides the Danuri website established by the ministry, many local governments have tried to bufld the necessary infrastructure in relation to offline and online support programsas well. For instance, the Seoul Metropolitan Government runs a bunch of global centers in the city. Seoul Global Center downtown is a comprehensive support center for foreign residents in Seoul. It offers a one-stop service regarding daily living, business activities, administrative services, various educational courses and international exchange events providing basic to specialize counseling on legal, labor, tax and real estate to help foreigners settle in Seoul.

The Global Village Centers are located in areas where a number of foreigners live. There are 7 centers in the city. The programs offered at the Global Village Center Services include support and information on daily living, educational programs, Korean and other languages classes, cultural programs, and volunteering programs. The websites of these centers are translated into 4 languages such as English, French, Chinese, and

${ }^{3}$ Korean, English, Chinese, Vietnamese, Tagalog, Russian, Cambodian, Mongolian 
Korean. Thus, it is not overstated that Seoul is prone to excluding the marriage immigrants from Southeast Asian countries.

In Gyeonggi Province where the largest immigrant population lives, there is the Center for Multicultural Education provides Korean citizens with multicultural education to understand other cultures. It also helps children from multicultural families improve a school performance by offering tutorial programs and mentoring services. However, it is mainly run on a person-to person basis so that the online system is not elaborately constructed to give appropriate information.

In regard of tourism information, Korea Tourism Organization establishes an official website to offer foreigners traveling around Korea with helpful information. As seen above, most of the websites related to multicultural families and foreigners offer helpful information to visitors, yet, they do not provide apps that can allow easy and immediate access to the information.

In addition, Hi Korea (http://www.hikorea.go.kr) is the main site of the e- government for foreigners, jointly created by the Ministry of Justice, the Ministry of Knowledge Economy and the Ministry of Labor in 2005. This portal site was made with the purpose of providing investment, employment, residence, and everyday information and services from a single source to foreigners visiting Korea or lixing in Korea Its service provides information through on-line electronic processing of yarious applications that are needed for residence and employment.

It also provides investment related services to potential forergn investors, for instance, including collecting information regarding potentral local parthers and connecting local firms to investors and various consulting services. The e-government for foreigners helps them enjoy same level of privileges and conyeniences as a Korean national [2].

\section{Development of Apps on Freign Language Basis}

As of December, 2012, ove 35 million people (70\% of the entire population) use smartphones in Korea, which defines this naton as one of the fastest IT adopters in the world [3]. Consequently, not only the apps for games, daily living, fun, but also the apps for industrial purposes are developed as well. Particularly, conglomerates, manufacturing businesses, governmental organizations, hospitals and schools actively utilize apps to improve their production efficiency.

In this regard, multicultural information for app users can be very helpful for immigrants to integrate into Korean society more independently by using apps customized according to their ethnic background. For example, a Canadian immigrant can be provided with a varfety of information in English by simply downloading an app.

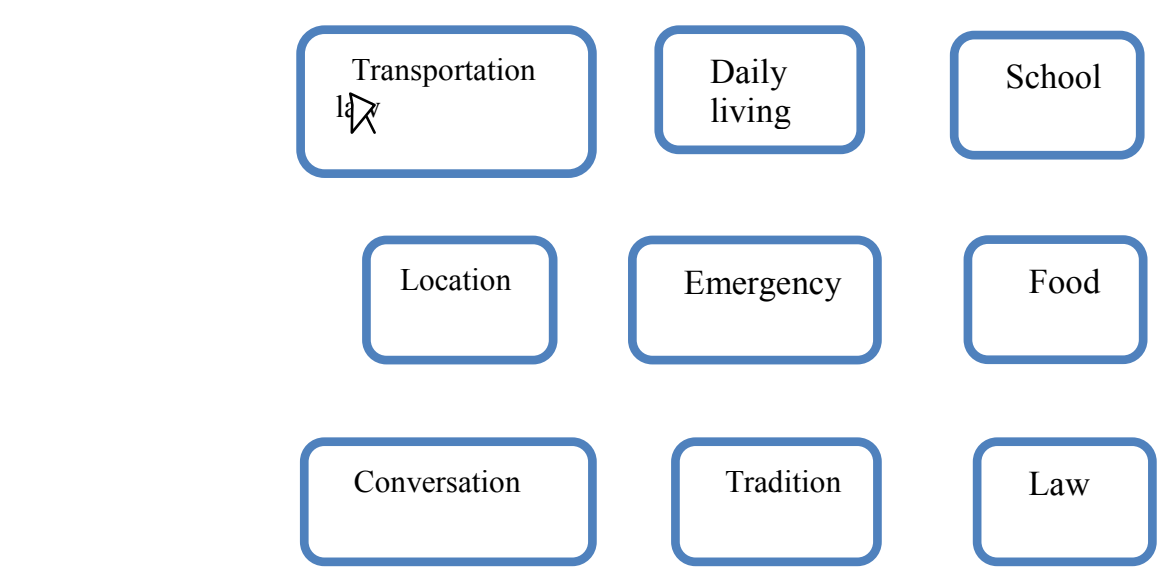

Figure 1. Information App for English-Speaking Immigrants 
If a user clicks one of the icons, he/she can approach enormous amount of information. The apps should be developed in foreign languages. The Transportation icon informs the user of the public transportation systems including bus lines, subway lines and express bus system and their routes, intervals, fares, transfer information, etc. The Food icon can play an important role to introduce Korean dishes to immigrants with recipes and nutrition values. The Emergency app is crucial in protecting people's lives and safety. The School app is very important for particularly marriage immigrants in regard of educating their child since Korean schools, more often than not, require parents to be actively involved in school activities. The Conversation and Tradition app help immigrants avoid frustrating situations caused by a language barrier. The Law can keep them from losing out due to lack of common sense in law.

\section{Conclusion}

Immigrants are required to acquire language competence that enables them to communicate and be aware of various information and knowledge in regard of living in Korea. Furthermore, they are anxious to keep in contact with information on theirmother country in order to maintain their identity and ease homesickness. The migrant workers and short term residents maybe need even more support because they are oo go back home after a certain period of time, which may lead to a social vacuum. Therefore, they should be given support to make a fresh start home. In this regard, their information literacy is significant.

As for marriage immigrants, it is not too much to emphasize that the abilities to run home economy and find necessary information are indispensible virtue in Korea, a highly wired society. That is, development of foreign language-based apps can achieve the improvement of marriage immigrants' iniormation literacy. In addition, it plays a major role to provide the convenience of the immigrants.

\section{References}

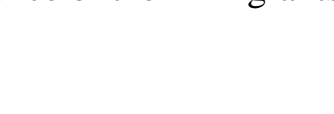

[1] Korea Immigration Service, The Monthly Statistics, (2012) December.

[2] E-government for Foreigners, www. Hikorea.go.kr.

[3] E. J. Cho, "Smartphone Users Reach 3.5 mil. Seoul Daily, (2012) December 27.

[4] Y. J. Lee and K W. Cho, "A Study on Improving Information Literacy of Marriage Immigrants through the Analysis of Marriage Immigrants Gatekeepers", Journal of Korea Biblia Society for Libiary and Information Science, vol. 21, no. 3, (2010), pp. 57-75.

[5] H. Y. Lee and S. J. Kwak, "A Study on Cooperation Networks for Multicultural Information Services", Journar or Korea Library and Information Science Society, vol. 43, no. 2, (2009), pp. 147-169.

[6] J. I. Ahn, "Digital Divide and Digital Literacy on the Perspective of Audience Welfare", Journal of Media and Information, no. 36, (2006), pp. 78-109.

[7] Y. J. Lee and H. Su Bae, "A study on Social Service and Information Accessibility of Female Marriage Immigrant s in Korea", Journal of Korea Library and Information Science, vol. 39, 10. $4,(2008)$, pp. 479-504.

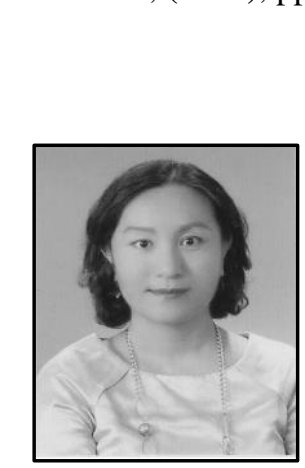

\section{Authors}

Jin-Young Kim, she received her Ph.D in Cultural Contents from Hankuk University of Foreign Studies in 2011. She joined as a lecturer in the Department of Global Culture and Contents of the same University. Her current research areas include eco-museum, multiculturalism, rural development, etc. 


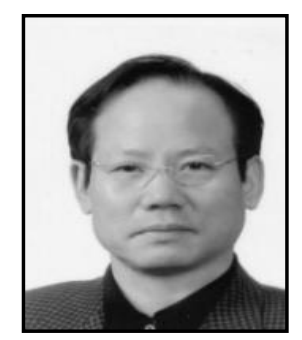

Jae Yeong Lee, he is a professor at Dept. of French, Hankuku University of Foreign Studies. He has been a president of Academic Association of Global Cultural Contents since 2012. He is interested in eco-museum, community mapping, local food system, rural revitalization, etc.

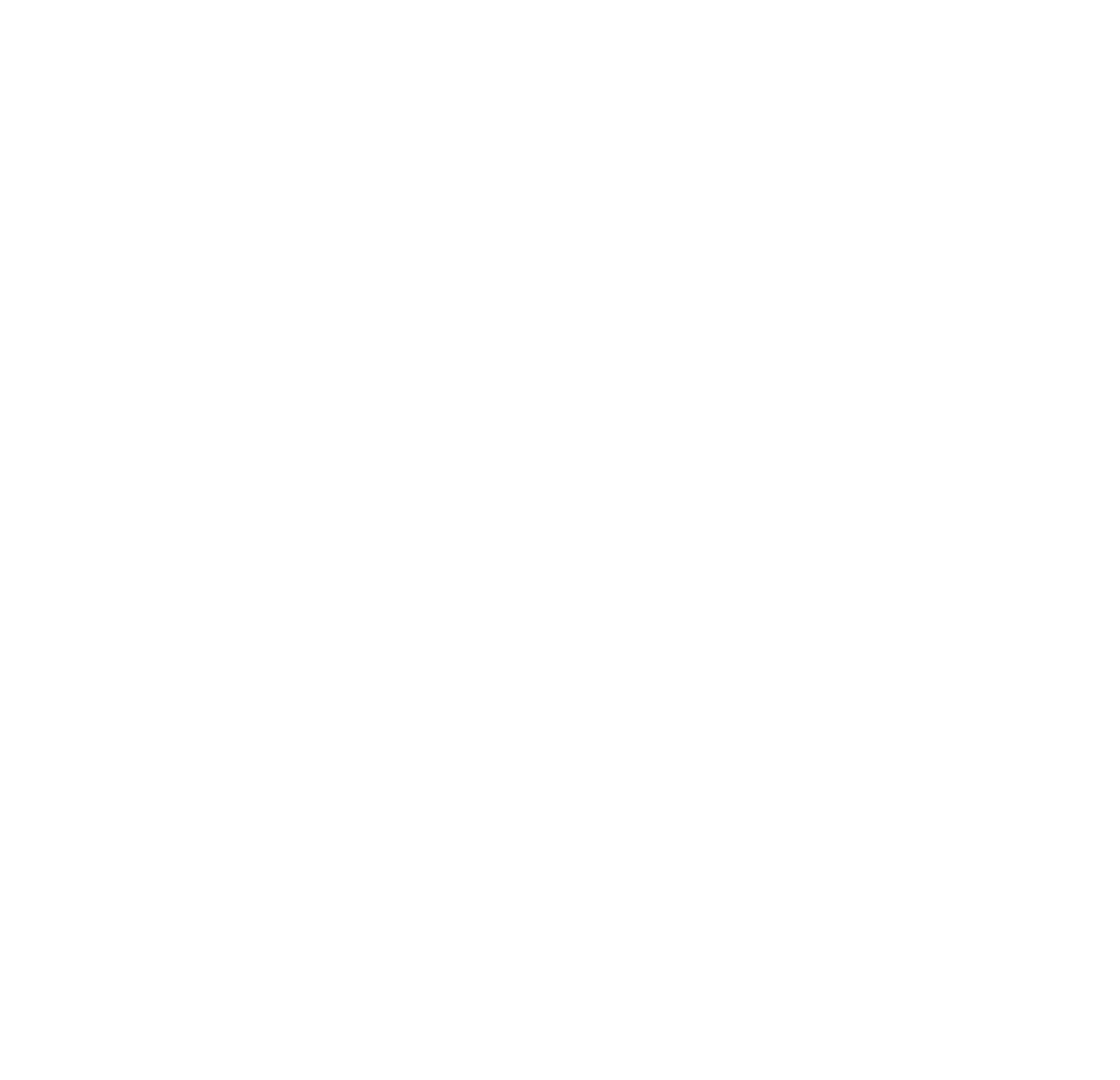

